\title{
Transtornos alimentares na visão de meninas adolescentes de Florianópolis: uma abordagem fenomenológica
}

\author{
Eating disorders in the view of teenage girls from Florianópolis, \\ Santa Catarina State: a phenomenological approach
}

Arlene Leite $\mathrm{N}_{\text {unes }}{ }^{1}$

Francisco deAssis Guedes deVasconcelos ${ }^{2}$

${ }^{1}$ Departamento de Psicologia, UNIVILLE. Campus Universitário $s / n$, Bom Retiro. 89219-905 Joinville SC.

arlenenunes@gmail.com

${ }^{2}$ Departamento deN utrição,

Centro deCiências da

Saúde, UniversidadeFederal deSanta Catarina.
Abstract The article aims to understand the meaning of theteenagers' experience of having ED (eating disorders), underscoring the aspects related to eating, from a phenomenological perspective. Seven female teenagers with ED being taken care in Florianópolis, Santa Catarina State, were interviewed. A categorization was made to reach the perception of the general structure of the experience, extracting the structure of the past experience. Nine signification units that assessed the life experience were identified: the representation of the food, eating habits, food that no longer were eaten, food that they had began eating, the use of soda, food choices, the composition of the meals, family eating habitsand healthy food. Theseshowed the suffering that permeates the existence of all the interviewed teenagers, whether for gaining weight, or not considering themselves thin enough, eating too much, not eating at all, forcing vomiting, taking laxatives and diuretics, trying to commit suicide, seeing the parents suffering, not feeling understood by the others, or by themselves. This research allowed us to study this phenomenon from another angle, the relation with the food, confirming how much the way our relation to food is connected to emotional matters. It also allowed showing how it is to live with an ED from the view of each of the interviewed teenagers.

Key words Eating disorder, Psychology, Phenomenology, Nutrition, Adolescents
Resumo 0 presente trabalho objetiva compreender o significado da experiência vivida por adolescentes do sexo feminino com transtorno alimentar (TA), com ênfase nos aspectos relacionados à alimentação, a partir de uma perspectiva fenomenológica. Entrevistamos sete adolescentes com TA, atendidas em hospitais e clínicas de Florianópolis (SC). $\mathrm{Na}$ análisedas entrevistas, procuramosidentificar as unidades de significado, categorizandoas para apreensão da estrutura geral da vivência, extraindo a estrutura do vivido. Foram identificadas nove unidades de significado: o que representa a comida, hábito alimentar, alimentos que deixaram de ser consumidos, alimentos que passaram a ser consumidos, consumo de refrigerantes, escolhas alimentares, composição das refeições, hábito al imentar da família e alimentação saudável. As unidades de significado revelaram, entre outros, o sofrimento das adolescentes, seja por engordar, não se achar magra suficiente, comer demais, não comer, provocar vômito, tomar laxante/diurético, tentar suicídio, ver pais sofrendo, não se sentirem compreendidas. A pesquisa proporcionou contemplar o fenômeno pelo prisma da relação com a comida, confirmando como esta relação está ligada ao emocional. Também mostrou como é viver com TA na visão das adolescentes, procurando enxergar esses transtornos segundo suas óticas e sentimentos.

Palavras-chave Transtorno alimentar, Psicologia, Fenomenologia, Nutrição, Adolescente 


\section{Introdução}

Transtornosalimentares (TA) constituem um conjunto dedoenças que afetam, principalmente, adolescentes e adultos jovens do sexo feminino, provocando marcantes prejuízos biológicos, psicológicos e sociais, propiciando o aumento das taxas de morbidade e mortalidade nesta população ${ }^{1}$.

OsprincipaisTA, anorexianervosa (AN) ebulimia nervosa (BN), apresentam características comuns que os assemelham, bem como características próprias que os distinguem. Porém, o padrão alimentar quecada pessoa desenvolveráéum fenômeno singular. 0 tipo de comida, frequência de consumo, quantidade ingerida apresentam um comportamento específico eindividual ${ }^{2,3}$.

Portanto, dentro de uma perspectiva fenome nológica, devemosolhar para cada indivíduo com esses transtornos como um ser único, suspender conceitos preestabelecidos sobre o queéou como deveria se apresentar um TA, procurando compreender a pessoa a partir da sua própria vivência. $\mathrm{N}$ as palavras de $\mathrm{H}$ eidegger ${ }^{4}$, a fenomenologia exprime "as coisas em si mesmas, [...] deixar e fazer ver por si mesmo aquilo que se mostra, tal como se mostra a partir de si mesmo".

Observamos que, em geral, as pesquisas têm discutido estes TA a partir de abordagens por vezes interpretativas e generalizadoras. Além disso, muitas vezes os TA não são vistos nem compreendidos com a seriedade que merecem, o que dificulta e retarda a busca por ajuda médica, psicológica e nutricional, fundamentais nos casos desses transtornos. A falta de conhecimento e de aceitação desses transtornos como doença prejudica ainda mais o indivíduo acometido podendo, até mesmo, levá-lo à morte ${ }^{1}$.

Acreditamos que é importante compreender e aprofundar os estudos acerca dos TA a partir da experiência vivida pelos sujeitos por eles acometidos. Assim, na presente pesquisa, buscamos dar voz a adolescentes acometidas por TA (AN e $B N$ ), procurando compreender o significado da experiência vivida a partir da seguinte questão norteadora: como adolescentes do sexo feminino com TA percebem e vivenciam sua relação com 0 alimento?

A proposta de estudar a nutrição aliada à psicologia se deu pelo desejo de compreendermos não apenas o que acontece no corpo da pessoa, mas também o que ocorre no plano emocional: o ser humano é um todo; portanto, deve ser visto e compreendido como tal. Não éapenas um ser que sente ou um ser quese alimenta. Eleé um ser que sente e se alimenta. Portanto, não é possível estudar o TA isolado do indivíduo, nem 0 indivíduo isolado do meio. Pessoas com AN ou BN normalmente não têm esses comportamentos apenas em relação à comida, relacionamse dessa forma frente à vida e aos sentimentos. São um todo 5 .

Este artigo apresenta parte dos resultados de uma pesquisa que teve como objetivo geral compreender o significado da experiência vivida por adolescentes do sexo feminino com AN e BN, com ênfase nos aspectos relacionados à alimentação, a partir de perspectiva fenomenológica. Desta forma, 0 artigo procura mostrar a percepção descrita pelas adolescentes a respeito de seus TA, focando a relação com o alimento e os hábitos alimentares.

\section{Percurso metodológico}

Esta pesquisa caracterizou-se como uma investigação denatureza qualitativa, centrada numaabordagem fenomenológica acerca da experiência vivida por adolescentes do sexo feminino com TA.

Realizada no município deFlorianópolis(SC), envolveu sete adolescentes diagnosticadas com TA (de acordo com o M anual estatístico ediagnóstico dos transtornos mentais ${ }^{3}$ ), sendo quatro com AN etrês com BN, na faixa etária de dezessete a vinte anos, atendidas no Hospital Infantil Joana de Gusmão, na Policlínica Regional eem consultório particular. As entrevistas foram realizadas no período de março a maio de2006, atéatingir o crité rio de saturação, que consiste no fenômeno que ocorre quando um certo número de dados coletados deixam de apresentar algo de novo para a compreensão fenomenológica ${ }^{6}$.

0 critério de inclusão das participantes neste estudo se deu em função da faixa etária, sexo e diagnóstico do transtorno em questão. Além disso, as participantes deveriam possibilitar o entendimento da questão norteadora, aceitar participar do estudo, comunicar-se sem quaisquer impedimentos ou limitações, ter a autorização dos pais ou responsáveis para participação eaceitar a condição das entrevistas serem gravadas.

As entrevistasforam realizadas deacordo com roteiro predefinido, composto de uma parte objetiva, procurando coletar dados para caracterização das entrevistadas, e outra subjetiva, com perguntas que variaram de acordo com o decorrer da entrevista, procurando captar a experiência vivida pelas entrevistadas acerca dos TA. As entrevistas foram realizadas pela pesquisadora, no local onde as adolescentes recebiam atendi- 
mento, eduraram em média 37 minutos, variando entre 23 e 58 minutos.

As entrevistas foram gravadas e transcritas na íntegra pela pesquisadora. Sigilo e anonimato em relação ao conteúdo foram garantidos, de modo a preservar a identidade das entrevistadas que escolheram um codinome para ser usado ao longo da entrevista e assinaram um termo de consentimento livre eesclarecido para participação na pesquisa.

A pós transcrição, para dar início à análise das entrevistas, seguimos passos apresentados na proposta de Amedeo Giorgi6-12, divididos em: 1) leitura da entrevista transcrita, com a intenção de captar o sentido no todo, diante do objeto de pesquisa; 2) nova leitura do texto, com o objetivo específico de discriminar unidades de significado, numa perspectiva psicológica, captando os momentos de mudança psicológica sensível de cada situação; 3) transformação das unidades em linguagem psicológica, de modo a chegar à expressão mais direta e explícita possível das percepções contidas na expressão do sujeito; 4) síntese de todas as unidades de significado, transformando-as num consistente relato da experiência do sujeito, chegando desta forma à estrutura da experiência ${ }^{6-12}$.

Encerrada essa etapa, objetivando dar sequência à análise dos dados, realizamos os seguintes trajetos metodológicos descritos por Coppe 1) construção de uma tabela contendo os dados deidentificação de cada participante, a descrição das unidades de significado, bem como a compreensão psicológica de cada uma delas, possibilitando-nos observar a síntese específica de cada participante; 2) categorização das unidades de significado para apreensão da estrutura geral da vivência, extraindo daí a estrutura do vivido; 3) elaboração de síntese geral, composta pela análi- se de todos os depoimentos, de modo a obter uma visão geral desse material. A partir dessa síntese, fizemos um diálogo reflexivo, articulando conteúdos empíricos e teóricos que nortearam nossa investigação.

O projeto foi aprovado pelos Comitês deÉtica em Pesquisa com Seres Humanos da Universidade Federal de Santa Catarina (projeto no 013/ 06) edo H ospital Infantil Joana de Gusmão (projeto $n=016 / 2006$ ).

\section{Resultados}

Breve perfil das adolescentes entrevistadas

$\mathrm{Na}$ Tabela 1, apresentamos um breve perfil das sete adolescentes entrevistadas, procurando listar algumas informações consideradas importantes para uma melhor compreensão do fenômeno estudado. A faixa etária atual das adolescentes entrevistadas variou entre dezessete e vinte anos. Quanto ao tipo de TA e à fase de tratamento, quatro tinham diagnóstico de $\mathrm{AN}$ ( $\mathrm{Bi}, \mathrm{Ca}, \mathrm{Ci}$ e $\mathrm{Mi}$ ) e três de BN (Ni, Lee Ju). Uma delas está em tratamento, mas não admite que tem TA, encontrando-se em estado grave (Bi); três estão em tratamento eadmitem quetêm TA ( $\mathrm{Ni}$, LeeJu); duas estão em tratamento em fase de recuperação ( $\mathrm{Ca}$ e Mi) euma não está em tratamento, mas admite quetem TA eque precisa detratamento ( $\mathrm{Ci}$ ). Com relação ao local deatendimento, uma (Bi) era procedente do Hospital Infantil Joana de Gusmão (HIJG); quatro ( $\mathrm{Ni}, \mathrm{Ca}$, Ju e Ci), da Policlínica Regional e duas (Lee Mi) de consultório particular. Embora as adolescentes entrevistadas se encontrassem na faixa etária entre dezessete e vinte anos, o transtorno manifestou-se entre onze e dezoito anos, sendo que o tempo de transtorno

Tabela 1. Descrição das adolescentes portadoras de TA entrevistadas, de acordo com idade, escolaridade, transtornos alimentares, fase do tratamento, idade do início do transtorno alimentar, duração do transtorno. Florianópolis, 2006.

\begin{tabular}{lclcl}
\hline Codinome & $\begin{array}{c}\text { Idade atual } \\
\text { (anos) }\end{array}$ & \multicolumn{1}{c}{ Escolaridade } & $\begin{array}{c}\text { Tipo de } \\
\text { transtorno }\end{array}$ & \multicolumn{1}{c}{$\begin{array}{c}\text { Fase de tratamento do } \\
\text { transtorno alimentar (TA) }\end{array}$} \\
\hline $\mathrm{Ni}$ & 17 & Ensino médio completo & BN & Em tratamento, admite que tem TA \\
$\mathrm{Bi}$ & 17 & 2o ano ensino médio & AN & Em tratamento, não admite que tem TA (estado grave) \\
$\mathrm{Lê}$ & 17 & 3o ano ensino médio & BN & Em tratamento, admite que tem TA \\
$\mathrm{Ca}$ & 19 & Superior incompleto & AN & Em tratamento, recuperação \\
$\mathrm{Ju}$ & 20 & Ensino médio completo & BN & Em tratamento, admite que tem TA \\
$\mathrm{Ci}$ & 20 & Superior incompleto & $\mathrm{AN}$ & Parou o tratamento, admite que tem TA \\
$\mathrm{Mi}$ & 20 & Superior incompleto & $\mathrm{AN}$ & Em tratamento, recuperação
\end{tabular}


estava entre um enove anos. Com relação à escolaridade, todas se encontram entre o ensino mé dio e o ensino superior incompleto.

$\mathrm{Na}$ Tabela 2, apresentamos dados relacionados a características antropométricas das entrevistadas. $D$ as adolescentes com diagnóstico de AN ( $\mathrm{Ca}, \mathrm{Mi}, \mathrm{Ci}$ e Bi), duas ( $\mathrm{Bi}$ e $\mathrm{Ca}$ ) continuam com IMC abaixo de $18,5 \mathrm{~kg} / \mathrm{m}^{2}$, uma (Mi), que está em processo de recuperação, apresenta IM C normal, e uma ( $\mathrm{Ci}$ ) não apresenta valores para IM C por não ter informado o peso atual. Apenas uma delas ( $\mathrm{Bi}$ ) permanece com o IMC abaixo de $17,50 \mathrm{~kg} / \mathrm{m}^{2}$, justamente a adolescente que ainda não admite ter um TA, encontrando-se em estado considerado grave.

Ao se observar o peso mínimo atingido, verificamos que todas as quatro adolescentes com diagnóstico de $\mathrm{AN}$ ( $\mathrm{Ca}, \mathrm{Mi}, \mathrm{Ci}$ e Bi) encontramsecom IM C abaixo do considerado normal. Além disso, três delas ( $\mathrm{Ca}, \mathrm{Mi}$ e Bi) apresentaram IM C abaixo $16,00 \mathrm{~kg} / \mathrm{m}^{2}$, atingindo, desta forma, estado de magreza grave. Interessante observar que, quando se trata do peso máximo atingido, nenhuma das quatro ( $\mathrm{Ca}, \mathrm{Mi}, \mathrm{Ci}$ e Bi) ultrapassou - IM C considerado normal, sendo que o índice mais al to foi o de $23,01 \mathrm{~kg} / \mathrm{m}^{2}$, bastante longe do limitemáximo da faixa de peso normal. Além disso, uma das adolescentes (Bi), mesmo quando atingiu seu peso máximo, ainda encontrava-se abaixo do considerado normal, e dentro da faixa dosTA. $O$ IM C máximo atingido foi $17,35 \mathrm{~kg} / \mathrm{m}^{2}$.

Ao se observar a perda de peso dessas adolescentes com diagnóstico de AN, constatamos uma redução de 20,83 (Ca) a 44,74\% (Bi) do peso, sendo que a quantidade de peso mínima perdida foi de dez quilos ( $\mathrm{Ca}$ ) e a máxima foi de dezenove quilos (M i).
Com relação às adolescentes com diagnóstico de BN ( $\mathrm{Ni}$, Le e Ju), observamos que todas se encontram atualmente com IMC normal e apenas uma delas ( $\mathrm{Ni}$ ) apresentou esteíndiceabaixo do normal, ao se considerar o peso mínimo.

Com relação ao peso máximo atingido, apenas uma das adolescentes (Ju) chegou a um índice considerado sobrepeso (acima de $25 \mathrm{~kg} / \mathrm{m}^{2}$ ), enquanto que as demais ( $\mathrm{Ni}$, Le) apresentaram, assim como as adolescentes com diagnóstico de AN, I M C considerado normal, também bastante longe do limite máximo da faixa de peso normal, sendo queo índicemáximo atingido foi 21,63 $\mathrm{kg} / \mathrm{m}^{2}$, inferior inclusiveao encontrado no índice máximo de AN .

No que concerneà perda de peso dessas adolescentes com diagnóstico de BN, constatamos uma redução de 9,26 (Le) a 25,76\% (Ju) do peso, sendo quea quantidademínima depeso perdido foi de cinco quilos (Le) e a máxima foi de dezessete quilos (Ju).

Conteúdo das entrevistas

e suas unidades de significado

Com relação à questão norteadora de como adolescentes do sexo feminino com TA percebem evivenciam sua relação com 0 alimento, a análise das entrevistas trouxe à tona nove unidades de significado, a saber: 1) o que representa a comida; 2) hábito alimentar; 3) alimentos que deixaram de ser consumidos; 4) alimentos que passaram a ser consumidos; 5) consumo de refrigerantes; 6) escolhas alimentares; 7) composição das refeições; 8) hábito alimentar da família e 9) alimentação saudável.

Tabela 2. Descrição das adolescentes portadoras de TA entrevistadas, de acordo com estatura, peso atual, mínimo e máximo, peso perdido, índice de massa corporal (IMC) atual, mínimo e máximo. Florianópolis, 2006.

\begin{tabular}{lcrrrrrr}
\hline Codinome & $\begin{array}{c}\text { Estatura* } \\
(\mathrm{m})\end{array}$ & $\begin{array}{c}\text { Peso*atual } \\
(\mathrm{kg})\end{array}$ & $\begin{array}{c}\text { Peso*mínimo } \\
(\mathrm{kg})\end{array}$ & $\begin{array}{c}\text { Peso*máximo } \\
(\mathrm{kg})\end{array}$ & $\begin{array}{c}\text { Peso*perdido } \\
(\mathrm{kg})\end{array}$ & $\begin{array}{c}\text { Peso*perdido } \\
(\%)\end{array}$ & $\begin{array}{c}\text { IM C**atual } \\
\left(\mathrm{kg} / \mathrm{m}^{2}\right)\end{array}$ \\
\hline $\mathrm{Ni}$ & 1,62 & 52 & 46 & 54 & 8 & 14,81 & 19,81 \\
$\mathrm{Bi}$ & 1,48 & 38,3 & 21 & 38 & 17 & 44,74 & 17,48 \\
$\mathrm{Le}$ & 1,58 & 54 & 49 & 54 & 5 & 9,26 & 21,63 \\
$\mathrm{Ca}$ & 1,59 & 45 & 38 & 48 & 10 & 20,83 & 17,80 \\
$\mathrm{Ju}$ & 1,52 & 52,5 & 49 & 66 & 17 & 25,76 & 22,72 \\
$\mathrm{Ci}$ & 1,51 & Não sabe & 37 & 50 & 13 & 26,00 & - \\
$\mathrm{Mi}$ & 1,56 & 48 & 37 & 56 & 19 & 33,93 & 19,72 \\
\hline
\end{tabular}

* Os dados de peso eestatura foram referidos pelas adolescentes; ** O IM C foi calculado com base nos dados antropométricos referidos. 
0 que representa a comida

O termo comida, em seu sentido vernáculo, significa: "1. 0 que se come ou é próprio para se comer. 2. Ação de comer"13. M as, para as adolescentes entrevistadas, na maioria dos casos, a comida tinha um significado bem diferente, remetendo a algo negativo:

Hum, assim, tortura ( $\mathrm{Ni}$ ).

Representava pavor, assim, eu tinha medo (Ca).

Eu acho uma coisa muito ruim (Bi).

Fuga, uma decadência, droga (Le).

Para algumas das adolescentes entrevistadas, a comida era uma obrigação, algo que tirava a liberdade:

É necessária, é obrigatória, mas eu não queria quefosse (Ju).

Se eu não fosse obrigada a comer, talvez seria bom (Bi).

M e sentir mais livre quando não como (Le).

Outras comentaram o lado positivo da comida:

Apesar que é bom. As comidas que tu gosta (Ni).

Alimento quefaz bem. A comida hoje pra mim é boa, é gostosa ( $\mathrm{Ca}$ ).

Hábito alimentar

A formação do hábito alimentar éinfluenciada por vários fatores - fisiológicos, psicológicos, socioculturais, econômicos - e ocorre à medida que a criança vai crescendo, até o momento em queescolherá conscienteeindependentementeos alimentos que farão parte da sua dieta ${ }^{14}$.

$\mathrm{N}$ as entrevistas que integraram esta pesquisa, observamos, por parte das adolescentes, uma preocupação com o controle da al imentação, tanto por si só, quanto com acompanhamento nutricional:

Ah, tal hora eu vou comer, não, agora eu não vou comer, vou esperar mais um pouco, tem que dar tantas horas, tomo café, tantas horas, eu almoço, mais de tardinha eu tomo café (Ci).

$\mathrm{H}$ oje eu vejo que eu comia completamente errado ( $\mathrm{Ca}$ ).

M as como tudo na quantidade certa. Como eu tenho acompanhamento nutricional com a nutricionista, eu como de tudo (M i).

Aí, sei lá, tudo controlado. Eu faço dieta, com a nutricionista agora (Le).

Alguns de seus relatos demonstraram haver intenção deaderir a uma alimentação considerada por elas saudável:

Eu não sou decomer verdura nem legume, nada assim, não como. Comer uma coisa mais leve, apesar que não é isso que eu gosto, né! ( $\mathrm{Ni}$ ).
Só não como muita coisa com gordura. Eu gosto de comer fruta, melancia. Eu sempre como sanduíchenatural [quando comeno shopping] (Bi).

Agora eu tô fazendo dieta mesmo. A minha alimentação foi meio reduzida. Eu como bastante fruta também. Sou vegetariana, aí eu tenho que comer soja e bastante barrinha de proteína (Le).

Porém, esta alimentação considerada saudável nem sempreéa preferida dessas adolescentes:

Eu não tava comendo comida, eu tava comendo pão, uma coisa que eu não comia antes, assim. U ma coisa que eu tô comendo mais é carboidrato, direto e tal. Gosto de massa, porcaria, salgadinho (Ni).

Assim comia chocolate. Às vezes me dava vontade de comer um brigadeiro, eu comia, mas sem peso na consciência ( $\mathrm{Ca}$ ).

M as eu gosto muito de doce, aí eu posso comer doce também, posso comer uma barra dechocolate pequeninha por dia (Le).

Quando eu era pequena eu comia bastante[ fast food] (Bi).

É interessante observar como várias das adolescentes entrevistadas frisaram o fato de estarem comendo:

M as eu tô comendo, não tô deixando de comer (Ci).

Como de tudo (Bi).

M as eu como, eu como tudo que eu gosto, como arroz, como feijão, todos os dias (Mi).

Sei lá, aí eu como (Le).

Comi pão, comi carne, arroz, tudo (Bi).

Alimentos que deixaram

de ser consumidos

A alimentação e a dieta têm um importante papel no desenvolvimento e na manutenção dos TA. Pessoas com esses transtornos apresentam graves restrições dietéticas, padrões e hábitos alimentares inadequados devido a uma série de fatores como falsos mitos e crenças, sensação de incompetência para lidar com o alimento, medo de engordar ${ }^{15}$.

Os principais alimentos que deixaram de ser consumidos pelas adolescentes entrevistadas foram aqueles por elas considerados "besteira" chocolate, por exemplo - independentementede elas gostarem ou não desses alimentos:

Chocolate. Eu gosto tanto, mas eu não tô comendo. $M$ ais besteira, assi $m$, sabe, que eu restrinjo. Bala, chicletes, chocolate ( $\mathrm{Ci}$ ).

Chocolate. Pipoca, essas coisas assim, nem pen$\operatorname{sar}(\mathrm{Ca})$.

Não gosto hoje [chocolate, bala, batata frita] (Bi). 
Além desses, outros alimentos, como pão, frutas e carne vermelha, deixaram de ser consumidos. As frituras, além de deixarem de ser consumidas, foram associados a fatores negativos por algumas das adolescentes:

Eu não como fritura. Eu tenho nojo ainda de fritura (Ca).

Eu tinha deixado de comer carnevermelha. Eu deixei de comer fritura. Fico pensando que não vai fazer bem pro meu corpo (M i).

Eu tinha deixado de comer pão ( $\mathrm{Ni}$ ).

Deixei de comer fruta (Ju).

N os TA, a relação com a comida é tão distorcida que, por vezes, torna-se difícil até mesmo descrever o quefoi deixado de comer, como ocorreu com esta adolescente:

Eu não vou dizer que eu parei de comer muito, eu perdi a noção do que eu como. Parece que é só comida, não tem muita distinção, então eu não sei te dizer exatamente o que eu parei, o que eu come cei, fica meio nublado (Le).

\section{Alimentos que passaram}

a ser consumidos

Em nossas entrevistas, observamos a valorização do consumo de vegetais por al gumas adolescentes, como apontam outras pesquisas ${ }^{16}$, independentemente de gostarem ou não:

A pesar que eu não gosto [ vegetais], vou ter que aprender a gostar $(\mathrm{Ni})$.

Verdura foi uma coisa que eu aprendi a comer que eu não, não, nunca gostei muito ( $\mathrm{Ca}$ ).

U ma coisa que eu passei a comer que eu não comia muito é verdura ( $\mathrm{Mi}$ ).

Uma das adolescentes entrevistadas relatou ainda aumento no consumo de doces:

Doce eu passei a comer mais (Le).

Consumo de refrigerantes

0 consumo excessivo de refrigerantes por adolescentes é um problema mundialmente comum ${ }^{14}$, relatado também pelas adolescentes entrevistadas, que por vezes substituem por refrigerante as refeições ou a própria água:

A cordei às seis da tarde, daí depois eu não comi nada, só tomei refrigerante, outro vício meu. Não comi mais nada. Tomo um refri, alguma coisa, e fica difícil eu comer, né ( $\mathrm{Ni}$ )."

Tomo muito refrigerante. Dois litros por dia praticamente. De manhã, se eu acordo de manhã, é a primeira coisa que eu faço é ir tomar coca. De madrugada, acordou, deu sede, coca. Eu não tomo água, só na coca. M uito raro eu tomar água (Ju).
Escolhas alimentares

Vários fatores podem estar envolvidos na escolha dos alimentos, desde sinais originados no cérebro ou na periferia atéa força do hábito ${ }^{17}$. Alguns dos fatores apontados pelas adolescentes entrevistadas para as escol has alimentares foram a quantidade de calorias ou aquilo que engorda menos:

N ormalmente eu tô ol hando as calorias. É automático ( $\mathrm{Ni})$.

Antes eu tentava geralmente comer o que menos engordasse (Ju).

Eu sei o que é mais calórico, o que é menos calórico, então, quando eu acho que eu tô um pouco acima do peso, eu já sei o que eu posso comer (Mi).

No outro dia eu faço outra coisa pra comer, sabe, pra não comer de novo. Pra não engordar (Ci).

Outros fatores citados foram a vontade, 0 sabor, ou o gosto:

Se eu tô com vontade eu como, só que depois a consciência bate. Como porque eu tô com vontade de comer (Ju)."

De acordo com a minha vontade (Mi).

Pelo gosto também ( $\mathrm{Ni}$ ).

Tem sabor, tem aquela coisa gostosa de tu estar comendo ( $\mathrm{Ca}$ ).

Também fazem parte da escolha alimentar dessas adolescentes saladas e frutas:

Eu nem gosto tanto de salada, mas comia mais salada assim, emenos comida ( $\mathrm{Ci}$ ).

la comer bastantefruta, tomaria suco. Pão até que eu comeria (Bi).

Sou vegetariana, gosto de salada e doce, comeria o dia inteiro (Le).

Nos episódios do comer compulsivo que ocorrem nos TA, de acordo com as adolescentes entrevistadas, não há escolha dos alimentos a serem consumidos:

N ão escolho [compulsão], o que vier eu como. Geralmente éo que eu gosto muito (Ju).

$\mathrm{Na}$ compulsão, équenormalmente eu como, tô com fome, então vou comer isso (Le).

Um dos profissionais necessários em uma equipe que trabalha com pessoas com TA é o nutricionista, cujo papel está intimamenteligado com a questão das escolhas alimentares, possibilitando, com isso, estabelecer uma relação adequada com o alimento. Os depoimentos a seguir demonstram a influência deste profissional nas escolhas alimentares de al gumas das adolescentes entrevistadas: 
A nutricionista que escolhe. Ela deixa eu escoIher também, mas eu prefiro que ela escolhe porque é ruim, não sei o que eu gosto ( $\mathrm{Bi}$ ).

A gente [ ela ea nutricionista] tentou fazer um cardápio balanceado, no primeiro mês segui um cardápio à risca assim, daí depois a gentefoi adaptando pra fazer algumas modificações (Mi).

Eu não sabia fazer isso antes de ir na nutricionista, não sabia como comer e parar de sentir fome (Le).

Escolhas alimentares são decisões complexas ligadas não apenas ao alimento, como também à condições sociais, tradições culturais ea elementos irracionais. Além disso, o comer é também uma atividadesocial eo alimento éuma questão emocional ${ }^{18}$. Desde o começo de nossas vidas, a alimentação está entrelaçada com emoções, simbolismos e influências socioeconômicas e culturais. Desta forma, alimentar-se implica em fazer escolhas ${ }^{19}$.

\section{Composição das refeições}

De acordo com o Guia para escolha de alimento ${ }^{20}$, o dia alimentar de um indivíduo deveria ser distribuído em seis refeições: café da manhã, lanche da manhã, almoço, lanche da tarde, jantar e lanche da noite. $\mathrm{Na}$ nossa pesquisa, $\mathrm{O}$ número de refeições variou de três a oito por dia.

As adol escentes entrevistadas descreveram seu café da manhã da seguinte forma:

De manhã édifícil eu tomar café, quando durmo até mais tarde eu já almoço ( $\mathrm{Ni}$ ).

Eu acordo meio-dia, eu acordo já vou direto almoçar (Ju).

Ah, tem pão [um, um emeio], café[ uma xícara], normal assim ( $\mathrm{Ci}$ ).

No caféda manhã, como uma fatia de pão, com geléia e queijo minas light e nescau, café com leite (Ca).

Tem bolacha, pão, fruta eleite (Bi).

Caféda manhã sempretomo bastantecafécom leite, torrada com frutas, ou uma fruta, ou iogurte (Mi).

Q uando eu não estou de dieta, é um iogurte e uma fruta. M as só que, agora que eu tô de dieta, nessa última semana posso escolher entre um iogurte ou uma fruta. Só pra mim perder peso (Le).

Observamos que o café da manhã das adolescentes entrevistadas que o fazem é composto de alimentos considerados saudáveis. 0 lanche da manhãnem sempreéfeito, masquando acontece, também é composto por alimentos considerados saudáveis:

logurte light, ainda é tudo light ( $\mathrm{Ca}$ ).

Lanche eu não faço mais, agora faço tudo junto $(\mathrm{Bi})$.
É uma fruta e um iogurte, ou um café e duas torradas, ou uma barrinha de cereais (Mi). Fruta ou pão de queijo (Le).

Com relação aos alimentos consumidos no almoço pelas adolescentes pesquisadas, destacamos os seguintes depoimentos:

N ormalmente eu faço miojo, um pãozinho ou alguma coisa assim $(\mathrm{Ni})$.

Arroz, macarrão, comida bem normal, como carne, se tiver gordura, geralmente eu como, frango, tudo (Ju).

Como o que tem]: umas três col heres de arroz, um pouquinho defeijão. Bem pouquinho. U m pouquinho de carne. Batata, pouco também (Ci).

U mas três colheres de arroz, feijão, aí carne ou frango ou peixe e verdura $(\mathrm{Ca})$.

É uma fruta. Sou obrigada a comer carne, arroz e feijão. E um prato de salada (Bi).

Arroz integral, eu vario daí entre peixe, carne vermelha, bife grelhado, frango grelhado, frango assado, feijão esalada, bastante salada (M i).

Eu fico comendo, sei lá, pão (Le).

As refeições são muitas vezes preparadas pelas próprias adolescentes, sendo essa uma prática bastante comum nos TA, e isso se comprovou nos depoimentos das nossas entrevistadas:

Normalmente eu faço miojo, a minha mãe faz comida, mas eu não gosto de tar comendo ( $\mathrm{Ni}$ ).

Já tevefases deeu querer preparar o meu almoço, pra cuidar em tudo assim, pra não deixar ter óleo, tudo que engordasse (Ju).

Eu geralmente [preparo das refeições] (Ci).

Algumas das adolescentes entrevistadas se livravam da comida ou utilizaram desculpas para não comer:

Tem vezes que eu também não almoço ( $\mathrm{Ni}$ ).

Não tô com fome, não tô a fim de comer (Ju).

Dizia que não tava com fome (Mi).

Eu deveria fazer um prato de comida, mas não tem tempo (Le).

Quando eu tava bem em crise, às vezes, eu almoçava antes, longe assim, ou às vezes não comia, dava comida pro cachorro ( $\mathrm{Ci}$ ).

Nessa época eu escondia, eu costumava fugir, dava um jeito, ia muito pra sala, fingia que tava vendo tel evisão, costumava botar pouquinha comida, botava no lixo, dava pro cachorro (M i).

Ou então, a comida consumida, quando a consumiam, era na maioria das vezes, em pequena quantidade:

Não como muito no almoço. É o horário que eu como menos (Ju).

Ah, eu como muito pouco, pouquinho, assim (Ci).

O lancheda tarde, quando éfeito, assim como 
o da manhã, também é composto por alimentos considerados saudáveis pelas adolescentes entrevistadas:

Às vezes como uma coisa ou outra. U m salgadinho $(\mathrm{Ni})$.

É bem raro comer alguma coisa à tarde. (Ju).

Eu almoço, aí, quando eu volto [trabalho], eu tomo café $(\mathrm{Ci})$.

Biscoitinho, ou aquele integral light, ou club social. Tomo café com leite. Tomo uma vitamina (Ca).

Leite, suco, bolacha e fruta ( $\mathrm{Bi}$ ).

Repito o lanche da manhã, invento alguma coisa. Seis horas também, ou eu faço o café da manhã invertido (Mi).

São dois lanches. Fruta, iogurte, aquela bolacha, ou pão, pode ser, tem variedade, assim. Aí, quantidade controlada (Le).

Com relação aos alimentos consumidos no jantar, os depoimentos foram os seguintes:

Pão, uma salsicha ou margarina, alguma coisa assim epão, não fico meenchendo decoisarada ( $\mathrm{Ni}$ ).

Pão de trigo com queijo, presunto, ricota e alface e tomate. Já é mais saudável. Um empanado ou um sanduíche na hora do colégio, ou um pote de açaí com banana (Ju).

U ma maçã ou como uma bolacha sal gada (Ci).

U m pão, salada, com queijo minasou com hambúrguer de frango $(\mathrm{Ca})$.

Só leite e fruta (Bi).

Sanduíche, peito de peru, queijo light ou queijo cottage, pão e, dependendo pão light ou pão normal, salada, um copo de café, um copo de iogurte (Mi).

H ambúrguer de soja, que eu preciso comer um por dia (Le).

Algumas das adolescentes entrevistadas realizam ainda uma ceia:

U ma maçã ou uma fruta qualquer $(\mathrm{Ca})$.

A ceia também éleite e fruta ( $\mathrm{Bi}$ ).

E na ceia geralmente um café desnatado, uma banana, sempre alguma coisa assim (Mi).

Durante o final de semana, dois fatores se destacaram. Primeiro, acordar tarde e passar 0 restante do dia comendo "besteira", apesar de muitas das adolescentes entrevistadas afirmarem não comer, saindo, desta forma, totalmente do ritmo dos outros dias da semana:

No domingo, normalmente eu durmo até super tarde, eu viro o dia, vou acordar de noite. Tomo um refri, vou beliscando. É um dia que eu não como. U ma bolachinha ( $\mathrm{Ni}$ ).

Domingo eu acordo tarde, às vezes eu durmo até três horas da tarde no domingo, aí acordo, não como, senão é alguma besteirinha. U m sorvete ou uma sobremesa que tiver na geladeira ou um pedaço de bolo, ou uma coisa assim, aí à noite geralmente eu como lanche, domingo éo dia quase que eu menos como (Ju).

Por outro lado, um segundo fator se destacou em relação à alimentação no final de semana. Algumas das adolescentes entrevistadas afirmaram comer em excesso ou sentir mais fome por estarem ociosas:

Sábado que eu mais como, acordo meio-dia, daí eu almoço, daí eu fico a tarde inteira sábado sem fazer nada, daí tudo quevem eu vou comendo (Ju).

$\mathrm{N}$ o final de semana eu fico com maisfome porque não tem nada, não trabalho ( $\mathrm{Ci}$ ).

Final de semana se eu fico em casa, eu acabo ficando angustiada, eu acabo comendo demais (Le).

Hábito alimentar da família

Desde o nascimento, os pais têm papel fundamental no desenvolvimento dos hábitos alimentares de seus filhos, seja pelo tipo dealimentação que eles oferecem, seja pelos conceitos alimentares que transmitem, sendo que todos esses fatores têm influência na formação dos hábitos alimentares. A forma como a família organiza sua dieta - o tipo, a quantidadee a qualidade dos alimentos - pode constituir um fator de risco para o desenvolvimento de TA. M as, além disso, outro fator que tem um papel central é a relação que a família estabelece com a alimentação ${ }^{21}$.

A maioria dasadolescentes entrevistadas considerou seu jeito de comer parecido com o da família, como mostram estes depoimentos:

É [forma de comer da família parecida com a forma dela comer]. Bastante gordura, meu pai é mais preocupado assim, sabe, mas a minha mãe não, ébem, bem, ela não égorda, mas ela tem muita vontade de comer as mesmas coisas queeu, muita massa, não consegue comer um pão só no caféda tarde, sempre comendo um pouquinho exagerado, assim, eàsvezes horas sem comer também, ela come bem pouco, assi m, três r efei ções, ela acorda de manhã, ela não comedemanhã, ela almoça, ela almoça bem, aí toma café às seis horas da tarde, ela fica até às seis sem comer, e depois à noite ela come alguma coisa assim, sempre um lanche, alguma coisa de besteira ( $\mathrm{J}$ u).

[irmão] já era assim de comer comida mais saudável, assim, mas ele come bem, come ovo frito todo dia, mas ele faz bastante atividade física então. Lá em casa o pessoal era de fritura assim, a minha mãe, galinha frita. Antes a gente comia muita besteira, assim, queijo amarelo, a minha mãe sempre foi muito de chocolate, doce assim, 
sempre, sempre. 0 meu pai já sempre foi de uma alimentação bem saudável, assim, o prato dele, mais da metade ésalada, ele semprefoi assim, de muita fruta, muita verdura. Eu sempre gostei muito de fruta, mas verdura e salada eu tentava fugir o máximo assim, nunca tinha no meu prato e hojetem. Às vezes a minha mãe faz pro meu pai, que o meu pai gosta depeixefrito, edaquele frango frito ( $\mathrm{Ca}$ ).

Eu acho que já foi parecida [forma de comer da família com a forma dela comer], agora, não. Eu tento outros caminhos, eu tento comer o mínimo possível. M inha família é meio italiana, aí eles têm aquel enegócio demassa eaí eu tento não ligar muito pra isso. M as lá em casa o pessoal gosta de comer (Le).

Sob outro enfoque, mas no mesmo sentido, algumas das adolescentes entrevistadas consideraram o jeito de comer da família parecido com o próprio jeito, diferenciando apenas na quantidade:

Aham [forma de comer da família parecida com a forma dela comer]. A quantidade não. M inha irmã às vezes janta, minha vó janta, meu tio que mora com a gente também, mais eu assim [come pouquinho, só uma frutinha] (Ci).

Sim [ forma de comer da família parecida com a forma dela comer]. N ão. Isso não [ir diminuindo, diminuindo] ( $\mathrm{Bi})$.

É. É bem parecido assim [forma de comer da família com a forma dela comer]. Na minha família sempre tiveram o habito de comer muita verdura, fazem as refeições à mesa e todos juntos, nos horários. Os únicos costumes que eles não têm e que eu aderi são os lanches, né (Mi).

Outras, ainda, relataram que seu hábito alimentar atual sofreu influência do hábito alimentar familiar:

Sim [ forma de comer da mãe influenciou na forma dela comer]. Sim, porque daí eu como 0 que ela faz. Aí acabo indo, comendo as mesmas coisas que ela. Eu como o que ela traz da padaria assim, daí onde acaba eu tendo o mesmo hábito alimentar dela (Ju).

Aham [forma de comer da família influenciou na forma dela comer]. Tipo de comer, sempre comer pão no café, sabe, no almoço sempretem arroz, feijão, sabe, alguma carne. É, mais o tipo de comida, a quantidade, eu nunca fui de comer muito, assim. Eles comem bem, assim (Ci).

Caféda manhã sempretomo bastantecafécom leite, como é uma coisa que eu gosto muito, acho queé uma coisa que eu herdei da mãe ( $\mathrm{M} \mathrm{i}$ ).

Houve, outrossim, um relato segundo o qual a adolescente relatou que influenciou o hábito alimentar familiar, tornando-o mais saudável:
Eu meio que incentivei, obriguei, né, a família toda a comer mais assado, mais grel hado. M eu irmão que diz que eu ajudei a alimentação da família toda porque eu meio que incentivei todo mundo a comer coisas mais saudáveis, assim, né, eu que semprefaço salada e eu faço, eu não deixo muito a minha mãe fazer fritura. $\mathrm{H}$ oje, por causa de mim, ela [mãe] meio que evitou muita coisa, muita fritura, aprendeu a comer salada. Hoje eu encho o saco dela pra colocar salada, eu sempre faço bastante salada, então todo mundo assim, acabou se ajudando. Toda família se ajudou pra ninguém mais comer fritura. Eu sempre faço e a maioria acaba comendo, né, não tem jeito, peixe assado ou peixe grelhado, então foi bem bom ( $\mathrm{Ca}$ ).

A penas uma das adolescentes entrevistadas disse acreditar quesua forma de se alimentar não sofreu influências dos costumes alimentares da família:

Acho que não [forma de comer da família influenciou na forma dela comer]. Eu comia de tudo quando era pequena, assi $m$, verdura, legume. Pela minha mãeeu comia tudo quetinha pela frente (Ni).

E também apenas uma das adolescentes entrevistadas disse considerar seu jeito de comer diferente do jeito da família:

M eu pai normalmentealmoça na sala sozinho, ele gosta de ver TV etal, daí eu almoço assim com a minha mãe. É tão rápido assim, a gentenem tem tempo de olhar uma pra cara da outra ( $\mathrm{Ni}$ ).

A relação da família com a alimentação é importante, pois o momento das refeições vai além do seu aspecto nutricional. Constitui um momento de compartilhar, além do alimento, informações, atividades do cotidiano, mensagens, etc. ${ }^{21}$.

Alimentação saudável

$\mathrm{Na}$ descrição das adolescentes entrevistadas, o conceito de alimentação saudável foi bastante restrito:

Não muito exagerada, mas também não muito controlada, assim. Comer de tudo um pouco, nos horários certos ( $\mathrm{Ni}$ ).

Comer fruta, o que eu não como, ter horário certo pra comer, praticar um exercício físico pra ajudar nessa alimentação, e comer um pouco de cada, cada coisa do grupo alimentar, assim, sabe, um pouco de carboidrato, um pouco de cada coisa assim, pra não, pra balancear bem a alimentação assim, sabe. Eu acho queéo essencial, maséo mais difícil, assim (Ju).

Tu comer, não comer demais, assi m, lógico, não comer coisas com muita fritura, mas comer as coisas que tu gostas moderadamente, tipo, vou comer 
batata frita, mas só vou comer final de semana, vou comer chocolate, como pouquinho. M as não deixar de comer as coisas quetu gostas. M aséo que eu não faço ( $\mathrm{Ci}$ ).

Que faça você se sentir bem com você mesma. $N$ ão só assim, o queadianta uma mulher, que quer perder peso, mas o médico assim, não, vocênão vai emagrecer isso porque você tem que comer isso, isso e isso por dia. Aí a mulher vai ficar sendo infeliz. Isso não é saudável. Ela vai ter aquela alimentação, o corpo dela vai estar saudável, mas a mente dela não, não vai ficar satisfeita com o corpo dela. Que me faça não sentir fome. Só isso que eu queria. M as é, tô trabalhando isso (Le).

Constatamos, dessa forma, que essas adolescentes possuem um conhecimento sobre os princípios de uma alimentação equilibrada, embora, na maior parte das vezes, tenham atitudes quenão correspondam a este conhecimento, uma vez que, como já foi visto, o comer vai além da dimensão nutricional apenas, envolvendo também fatores emocionais, sofrendo influências tanto socioeconômicas como culturais $s^{18}$.

\section{Discussão}

Nos últimos anos, AN e BN tornaram-se importantes temáticas de discussão na mídia brasileira e mundial. Personagens de novelas do principal canal de TV aberta do país portadoras de quadros de AN e BN, manchetes de capas de re vistas, jornais e temática central de diversos programas de variedades, tanto na TV quanto no rádio, contribuíram para aumentar índices de audiência desses veículos de comunicação.

Toda essa discussão traz um aspecto positivo: a disseminação da informaçãao sobre esses TA pelos veículos de comunicação demassa, pois quanto antes for detectado um TA, maiores as chances de um bom prognóstico. À medida que a atenção das pessoas é chamada para os transtornos do comportamento alimentar e que a população toma conhecimento de sua existência, sintomas e consequências, maiores as chances de serem descobertos em tempo menor. Vistos muitas vezes como mania de adolescente, por conta da falta de informação, os episódios divulgados pelos meios de comunicação levam ao conhecimento do público leigo que a $\mathrm{AN}$ e a $\mathrm{BN}$ podem matar.

Em nossa pesquisa, consideramos queas pessoas mais indicadas para fornecerem informações a respeito dos TA eram os próprios indivíduos acometidos por essas patologias. Desta for- ma, com o objetivo de compreender o significado da experiência vivida por pessoas com TA, especificamente adolescentes do sexo feminino, fomos ao encontro delas. Esse contato nos permitiu conhecer suas vivências esentimentos relacionados direta e indiretamente a seus TA.

Descobrir o quesão TA não éuma tarefa muito difícil, uma vez que há inúmeros artigos científicos e vários livros descrevendo-os. Nossa proposta era mostrar como são esses transtornos na visão de quem está passando por eles.

No contato com as adolescentes entrevistadas, chamou-nos a atenção a disponibilidade em abrirem as portas de sua existência e compartiIharem a história de seus transtornos e de suas vidas, mesmo na presença do sofrimento quetantas vezes surgia diante de um silêncio profundo ou das lágrimas que quase, ou por vezes, caíam.

0 contato com essas adolescentes foi enriquecedor. As entrevistas possibilitaram descrever comportamentos, atitudes, sentimentos e percepções que nortearam nosso estudo.

Uma preocupação exacerbada com o controle da alimentação é a tônica comum dos TA, segundo a literatura ${ }^{18}$. Essa preocupação ficou evidenciada também em nossas entrevistas, tanto nas adolescentes que estavam em acompanhamento nutricional quanto as que não estavam. Há ainda a intenção de uma alimentação considerada por elas saudável, que nem sempre é a preferida dessas adolescentes, mas que, ainda assim, é adotada.

Observamos em nossas entrevistas que as escolhas alimentares normalmente são feitas de acordo com a quantidade de calorias ou com aquilo queengorda menos, mas, além disso, também influenciam na escolha a vontade, o sabor ou o gosto. Alguns depoimentos nos mostraram que as escolhas são feitas de acordo com a orientação das nutricionistas, destacan do a importância desse profissional no sucesso do tratamento. Porém, nos episódios de comer compulsivo, observamos que não há critério de escolha.

Com relação ao número de refeições realizadas pelas adolescentes da nossa pesquisa, encontramos relatos que vão de três a oito por dia, sendo distribuídas entre café da manhã, lanche matutino, almoço, lanche vespertino, jantar, lanche noturno, ceia e "extras". A maioria das adolescentes entrevistadas considera seu jeito de comer parecido com o da família; algumas consideram 0 jeito de comer da família parecido com o próprio, diferenciando apenas na quantidade. Outras ainda consideram que seu hábito al imentar atual sofreu influência do hábito alimentar familiar euma 
delas considera que ela influenciou o hábito alimentar familiar, tornando-o mais saudável.

Abordar os TA a partir do olhar da nutrição, aliado ao da psicologia, foi uma experiência extremamente rica, pois nos proporcionou contemplar estefenômeno por um outro prisma - 0 da relação com a comida - e confirmar o quanto a forma de se relacionar com a comida está ligada a questões emocionais. E, apesar do conhecimento teórico e da prática clínica com pessoas com TA, esta "interseção" da nutrição com a psicologia propiciou, ainda, ver algo relativamente conhecido com novos olhos.

Além disso, este estudo, durante a sua realização, nos provocou mudanças significativas, tanto nos aspectos pessoais quanto profissionais, abrindo questões para uma reflexão futura.

Com relação ao método adotado neste estudo, acreditamos que a escolha do método qualitativo, centrado numa abordagem fenomenológica, confirmou-se de fato o mais adequado de acordo com os objetivos propostos. 0 método adotado nos possibilitou o acesso ao conteúdo deforma profunda, não generalizadora nem tampouco interpretativa, como descreve H eidegger" "deixar e fazer ver por si mesmo aquilo que se mostra, tal como se mostra a partir de si mesmo".

\section{Consideraçõesfinais}

Esta pesquisa, conforme já apontado, buscou compreender o significado da experiência vivida de TA em vez de explicá-lo, pois na perspectiva fenomenológica adotada, é a compreensão do fenômeno que nos possibilita abranger sua totalidade em suas múltiplas dimensões. Desta forma, nos proporcionou mostrar como éviver com TA na visão de cada uma das sete adolescentes entrevistadas.

Porém, não podemos parar por aqui: é fundamental que mais estudos sejam feitos sobre estetema, especialmente dando espaço às pessoas portadoras dos TA que tanto nos têm a dizer. De suma importância também é a informação e a divulgação sobre esses TA, bem como sobre os tratamentos adequados e os profissionais indicados para contribuir nesses casos, numa tentativa de evitar que o sofrimento das pessoas acometidas passe despercebido e se prolongue por um tempo ainda maior ou - ainda mais grave leve a um desfecho trágico.

\section{Colaboradores}

AL Nunes foi responsável pela concepção e delineamento da pesquisa e redigiu 0 artigo. FAG Vasconcel os orientou a real ização do estudo efoi responsável pela revisão do artigo. 


\section{Referências}

1. Cordas TA. Transtornos alimentares: classificação e diagnóstico. Revista de Psiquiatria Clínica 2004; 31(4): 154-157.

2. Beumont PJV. The clinical presentation of anorexia and bulimia nervosa. In: Fairburn CG, Brownell $K D$, editors. Eating disorders and obesity: a comprehensive handbook. New York: The Guilford Press; 2002. p. 162-170.

3. DSM -IV-TR: M anual diagnóstico e estatístico de transtornos mentais. Porto Alegre: ArtM ed; 2002.

4. Heidegger M. Ser e Tempo (Parte I). Petrópolis: Vozes; 1989.

5. Ribeiro JP. Gestalt Terapia: refazendo um caminho. São Paulo: Summus; 1985.

6. Coppe AAF. A vivência em grupos de encontro: um estudo fenomenológico de depoimentos [dissertação]. Rio de Janeiro (RJ): U niversidade Federal do Rio de Janeiro; 2001.

7. Amatuzzi MM. Apontamentos acerca da pesquisa fenomenológica. Estudos de Psicologia 1996; 13(1):5-10.

8. França C. Psicologia fenomenológica: uma das maneiras de se fazer. Campinas: Editora da Unicamp; 1989.

9. Holanda AF. $O$ resgate da fenomenologia de Husserl e a pesquisa em psicologia [tese]. Campinas (SP): Universidade Católica de Campinas; 2002.

10. Holanda AF. Pesquisa fenomenológica e pesquisa eidética. In: Bruns MAT, Holanda AF. Psicologia e fenomenologia: reflexões e perspectivas. Campinas: Alínea; 2003. p. 41-64.

11. Martins J, Bicudo M AV. A pesquisa qualitativa em psicologia: fundamentos e recursos básicos. São PauIo: Centauro; 2003.

12. Moreira DA. 0 método fenomenológico na pesquisa. São Paulo: Pioneira Thomson; 2002.

13. Ferreira $A B H$. Minidicionário da Língua Portuguesa. Rio de Janeiro: Nova Fronteira; 2003.

14. Bandeira CRS, Fisberg M, Bonilha EA, Halpern G, Hischbruch MD. Hábitos alimentares na adolescência. Pediatria M oderna 2000; 36(11):724-734.
15. Alvarenga $M$, Larino MA. Terapia nutricional na anorexia e bulimia nervosas. Revista Brasileira de Psiquiatria 2002; 24(3):39-43.

16. Dunker KLL, Philippi ST. Hábitos e comportamentos alimentares de adolescentes com sintomas de anorexia nervosa. Revista de Nutrição 2003; 16(1):51-60.

17. Bacaltchuck J, Appolinário JC. Neurobiologia. In: Claudino AM, Zanella MT, organizadores. Guia de Transtornos Alimentares e O besidade. Barueri: Manole; 2005. p. 3-23.

18. Alvarenga M, Dunker KLL. Padrão e comportamento alimentar na anorexia e na bulimia nervosa. In: Philippi ST, Alvarenga M. Transtornos alimentares: uma visão nutricional. Barueri: M anole; 2004. p. 131-148.

19. Eisenstein E, Coelho K, Coelho S, Coelho M. Nutrição na adolescência. Jornal de Pediatria 2000; 76(3): 263-274.

20. Philippi ST, Latterzza AR, Cruz ATR, Ribeiro LC. Pirâmide alimentar adaptada: guia para escolha dos alimentos. Revista de Nutrição 1999; 12(1):65-80.

21. Cobelo AW. O papel da família no comportamento alimentar e nos transtornos alimentares. In: Philippi ST, Alvarenga M. Transtornos alimentares: uma visão nutricional. Barueri: Manole; 2004. p. 119-129.

Artigo apresentado em 25/06/2008

Aprovado em 30/10/2008

Versão final apresentada em 11/11/2008 